\title{
PROPERTIES AND EFFECTS OF HYDROGEN IN GaN
}

\author{
S.J. Pearton ${ }^{(1)}$, H. Cho ${ }^{(1)}$, F. Ren ${ }^{(2)}$, J.-I. Chyi ${ }^{(3)}$, J. Han ${ }^{(4)}$, R.G. Wilson ${ }^{(5)}$
}

${ }^{(1)}$ Department of Materials Science and Engineering, University of Florida, Gainesville FL 32611, USA

(2) Department of Chemical Engineering, University of Florida, Gainesville FL 32611, USA

(3) Department of Electrical Engineering, National Central University, Chung-Li 32054, Taiwan

(4) Sandia National Laboratories, Albuquerque NM 87185, USA

(5) Consultant, Stevenson Ranch, CA 91381, USA

\begin{abstract}
The status of understanding of the behavior of hydrogen in $\mathrm{GaN}$ and related materials is reviewed. In particular, we discuss the amount of residual hydrogen in MOCVD-grown device structures such as heterojunction bipolar transistors, thyristors and p-i-n diodes intended for high power, high temperature applications. In these structures, the residual hydrogen originating from the growth precursors decorates $\mathrm{Mg}$ doped layers and $\mathrm{AlGaN} / \mathrm{GaN}$ interfaces. There is a significant difference in the diffusion characteristics and thermal stability of implanted hydrogen between $\mathrm{n}$ - and $\mathrm{p}-\mathrm{GaN}$, due to the stronger affinity of hydrogen to pair with acceptor dopants and possibly to the difference in $\mathrm{H}_{2}$ formation probability.
\end{abstract}

\section{INTRODUCTION}

It is our experience that atomic hydrogen readily permeates into $\mathrm{GaN}$ during many different device processing steps. The indiffusion is likely to be strongly enhanced by the presence of the high defect density in heteroepitaxial material. Examples of the processes in which hydrogen is incorporated into $\mathrm{GaN}$ at low temperatures $\left(<300{ }^{\circ} \mathrm{C}\right)$ include plasma enhanced chemical vapor deposition of dielectrics (the source of the hydrogen can be the plasma chemistry or erosion of the photoresist mask), boiling in solvents (including water), annealing under $\mathrm{H}_{2}$ or $\mathrm{NH}_{3}$ ambients and wet etching in acid or base solutions (e.g. $\mathrm{NaOH}, \mathrm{KOH}$ ). Secondary Ion Mass Spectrometry (SIMS) profiling after processing with deuterated chemicals to enhance the detection sensitivity show that hydrogen can diffuse into $\mathrm{GaN}$ at temperatures as low as $80{ }^{\circ} \mathrm{C}$. The main effect of the hydrogen is passivation (electrical deactivation) of $\mathrm{Mg}$ acceptors in $\mathrm{p}-\mathrm{GaN}$ through formation of neutral $\mathrm{Mg}-\mathrm{H}$ complexes, which can be dissociated through either minority carrier (electron) injection or simple thermal annealing. There is evidence that all of the acceptor species in $\mathrm{GaN}$, namely $\mathrm{Mg}, \mathrm{C}, \mathrm{Ca}$ and $\mathrm{Cd}$ are found to form complexes with hydrogen.

In this paper we will summarize what is known about the effects of hydrogen in $\mathrm{GaN}$ and discuss new results on the incorporation of hydrogen in electronic device structures.

\section{PRESENT STATE OF KNOWLEDGE}


The following information is firmly established for the behavior of hydrogen in GaN.[1-26]

1. $\mathrm{GaN}(\mathrm{Mg})$ grown by atmospheric pressure Metal Organic Chemical Vapor

Deposition is highly resistive due to formation of neutral $\mathrm{Mg}-\mathrm{H}$ complexes.[18,21,22] The $\mathrm{Mg}$ can be activated (i.e. produce p-type conductivity) by post-grown annealing at $\geq 700{ }^{\circ} \mathrm{C}$ in $\mathrm{N}_{2}$ [22], low energy electron-beam irradiation near room temperature[18] or by forward biasing of a p-n junction to inject minority carriers (electrons).[27]

2. Thermal annealing in $\mathrm{NH}_{3}$ at $\geq 400{ }^{\circ} \mathrm{C}$ causes the $\mathrm{GaN}(\mathrm{Mg})$ to revert to a highly resistive $\left(>10^{6} \Omega \cdot \mathrm{cm}\right)$ state.[21,22]

3. $\mathrm{GaN}(\mathrm{Mg})$ grown by low-pressure MOCVD, Reactive Molecular Beam Epitaxy (solid $\mathrm{Ga}, \mathrm{NH}_{3}$ gas) or by plasma-assisted MBE (solid $\mathrm{Ga}$, plasma $\mathrm{N}_{2}$ ) can be p-type without annealing. This is presumably due to the lower $\mathrm{H}_{2}$ fluxes during growth, and the vacuum anneal undergone by RMBE material which is typically cooled without the plasma on.[28]

4. The residual hydrogen concentration in all $\mathrm{GaN}(\mathrm{Mg})$ tracks the acceptor concentration.[12]

5. All acceptor species show pairing with hydrogen (i.e. $\mathrm{Mg}, \mathrm{Zn}, \mathrm{C}, \mathrm{Ca}$, Cd).[13,18,21,29-31]

6. Donor dopant-hydrogen complexes have not yet been detected, and hydrogen concentrations are generally much lower in n-type GaN than in p-type material.[32]

7. Hydrogen enters $\mathrm{GaN}$ during many different device processing steps, even at $100{ }^{\circ} \mathrm{C}$ or lower.[11]

Information that is not as firmly established includes the following:

1. The energy levels and charge states $\left(\mathrm{H}^{\mathrm{o}}, \mathrm{H}^{+}, \mathrm{H}^{-}\right)$of hydrogen in $\mathrm{GaN}$.

2. The existence of hydrogen molecules or larger clusters.

3. The role of hydrogen in facilitating p-type doping. Van Vechten[26] has suggested that hydrogen compensates native defects, making p-type doping possible, while Neugebauer and Van der Walle[14,19] built on an earlier idea of Neumark's[33] from II-VI compounds that the presence of hydrogen increases $\mathrm{Mg}$ solubility and decreases compensating native vacancy defect concentration in $\mathrm{GaN}$.

4. The role of line and point defects in enhancing hydrogen diffusivity (this will be answered by a comparison of its incorporation in the new epitaxial lateral overgrowth material with conventional heteroepitaxial $\mathrm{GaN}$ ).

5. Hydrogen solubility - as with other semiconductors, the apparent solubility at low temperatures $\left(\leq 500{ }^{\circ} \mathrm{C}\right)$ is likely to be dominated by the concentration of sites to which the hydrogen can be bonded, i.e. dopants, defects and impurities.[34] In the following sections we will cover the incorporation of hydrogen during growth and processing, its thermal stability in $\mathrm{GaN}$ and some of the complexes it forms with dopants and defects.

\section{HYDROGEN IN AS-GROWN GaN}

As mentioned above, the hydrogen concentration in $\mathrm{p}-\mathrm{GaN}$ tracks the $\mathrm{Mg}$ concentration, and is correlated with the active $\mathrm{Mg}$, not the total $\mathrm{Mg}$ density. Since $\mathrm{Mg}$ has a relatively deep ionization level (160-170 meV), the hole concentration at room temperature is typically only a percent or so of the total $\mathrm{Mg}$ in the crystal. We have found typical hydrogen concentrations in the $10^{18}-10^{19}$ range in virtually all GaN grown by gas- 
phase techniques; in some samples doped with $\mathrm{Si}$, we have seen the hydrogen present at higher concentrations $\left(10^{20} \mathrm{~cm}^{-3}\right)$, similar to that of the $\mathrm{Si}$ (Figure 1). This suggests the possibility of (Si-H) pair formation, but more work must be done to confirm this idea. It is a general result in semiconductors that acceptor passivation by hydrogen is more thermally stable than donor passivation and therefore is more readily observed experimentally.[34]

For the case of

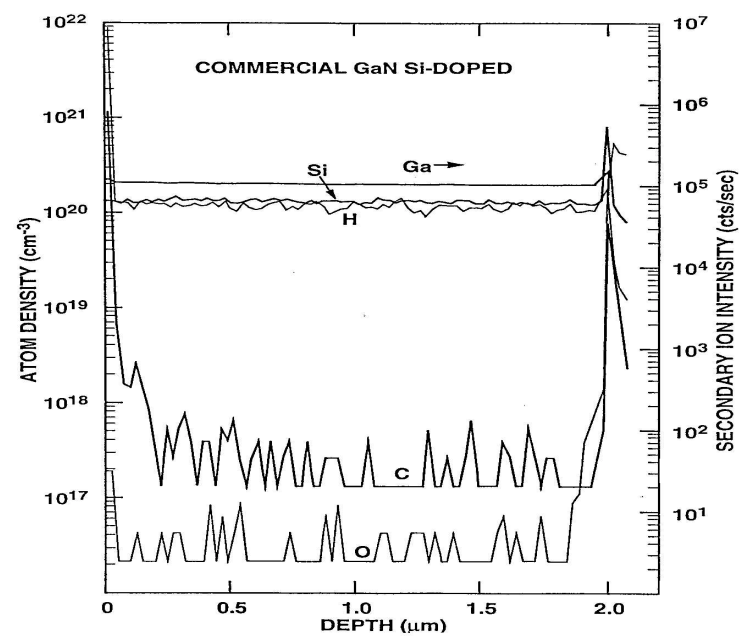

Figure 1. SIMS profiles of $\mathrm{H}$ and other background impurities in MOCVD-grown, Si-doped GaN

$\mathrm{p}-\mathrm{GaN}$, the hydrogen concentration is usually the same as the active $\mathrm{Mg}$ (i.e. $\sim 1 \%$ of $10^{20} \mathrm{~cm}^{-3}$ ) after growth. A $700{ }^{\circ} \mathrm{C}, 20$ min post-growth anneal in $\mathrm{N}_{2}$ only reduces the hydrogen concentration by a factor of 2 or 3, but this is enough to have strong p-type conductivity. An interesting question is whether the hydrogen is present in the GaN at the growth temperature (where it would be unbound and extremely diffusive) and then settles on the $\mathrm{Mg}$ during cooldown, or whether it actually enters the GaN from surface cracking of $\mathrm{NH}_{3}$ (to $\mathrm{N}_{2}, \mathrm{NH}_{\mathrm{x}}$ and $\mathrm{H}$ ) during cooldown after growth (probably in the temperature range $300-600{ }^{\circ} \mathrm{C}$ ). The latter is the passivation mechanism in p-type $\mathrm{InP}$ and $\mathrm{GaAs}$ grown by MOCVD, where hydrogen is found to deactivate 10-60\% of $\mathrm{Zn}$ or C acceptors.

The annealing ambient may also affect the apparent thermal stability of the passivation, with reactivation of passivated $\mathrm{Mg}$ occuring at lower temperatures for $\mathrm{N}_{2}$ anneals. This is also a familiar phenomenon from other semiconductors. Since reactivation of the acceptor only requires dissociation of the $\mathrm{Mg}-\mathrm{H}$ complex and a short range diffusion of the hydrogen away from the acceptor, it is also found that the apparent reactivation temperature depends therefore on the doping concentration (and therefore the associated hydrogen concentrations) and the layer structure and thickness (e.g. heteroepitaxial materials cladding the $\mathrm{p}-\mathrm{GaN}$ layer may serve to retard hydrogen outdiffusion).

In contrast to other semiconductors in which acceptors are passivated by atomic hydrogen occupying a bond-centered position between the dopant and a neighboring lattice atom, in $\mathrm{GaN}$ the ionicity of the bonds means there is no local maximum in the charge density at the bond center. Both theoretical[14] and experimental[23] evidence suggests that in $\mathrm{GaN}(\mathrm{Mg})$ the hydrogen attaches to a nitrogen atom in an antibonding orientation. The predicted stretch frequency of hydrogen in the $\mathrm{Mg}-\mathrm{H}$ complex is 3360 $\mathrm{cm}^{-1}$,[14] similar to that in $\mathrm{NH}_{3}$ molecules $\left(3441 \mathrm{~cm}^{-1}\right)$. Experimentally, a frequency of $3125 \mathrm{~cm}^{-1}$ has been reported.[23] 


\section{HYDROGEN IN AS-GROWN DEVICE STRUCTURES}

There is a lot of
interest in the development of
GaN-based high power, high
temperature electronics for
power switching and
microwave applications. One
potential device for ultra-high
power switching is a thyristor,
in either the npnp or pnpn
configurations. Figure 2 shows
a SIMS profile of Mg and $\mathrm{H}$ in
an MOCVD-grown npnp
thyristor structure. Note how
the residual hydrogen tracks the
Mg. Since the Mg-doped layer
at $~ 5.5 \mu$ mepth was the first
to be grown, it contains less
hydrogen than the Mg-doped
region nearer to the surface
which has spent less time at the
growth temperature of $1040{ }^{\circ} \mathrm{C}$.
The source of the hydrogen is

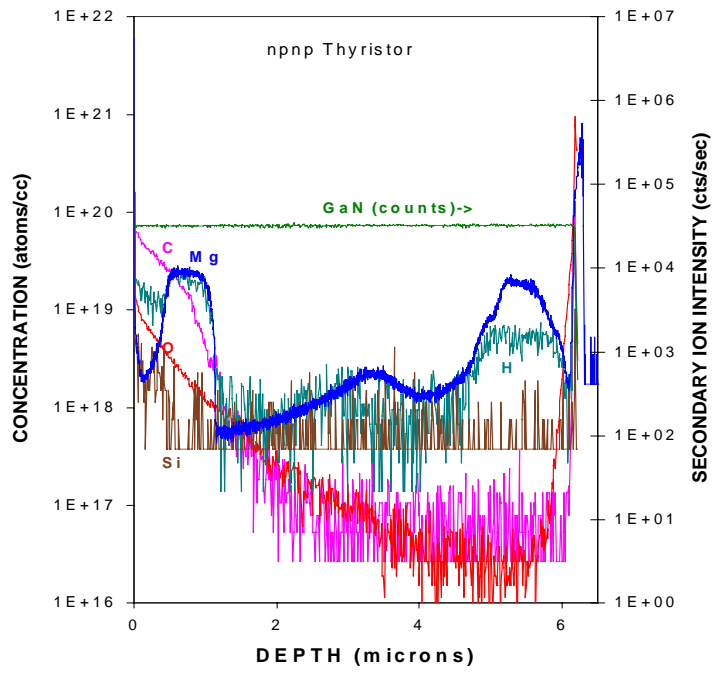

Figure 2. SIMS profiles of $\mathrm{H}$ and other background impurities in an MOCVD-grown npnp thyristor structure.

either the precursors, $\left(\mathrm{CH}_{3}\right)_{3} \mathrm{Ga}$ and $\mathrm{AsH}_{3}$, or the carrier gas, which is generally $\mathrm{H}_{2}$. Sugiura et.al.[17] found that if they employed a $\mathrm{N}_{2}$ carrier gas, they could get $\mathrm{p}-\mathrm{GaN}$ without post-growth annealing. They also found that using a mixed $\mathrm{H}_{2} / \mathrm{N}_{2}$ carrier gas reduced the p-type doping level in asgrown samples. These results implicate the $\mathrm{H}_{2}$ carrier gas as the main source of hydrogen for passivation of the $\mathrm{Mg}$ acceptors, but previous experience in MOCVD growth of highly doped $\mathrm{p}$-GaAs suggests that both the $\left(\mathrm{CH}_{3}\right)_{3} \mathrm{Ga}$ and $\mathrm{AsH}_{3}$ are likely to also play a role. In particular, the cool down in $\mathrm{AsH}_{3}$ ambient after growth is likely a source of hydrogen for passivation.

Schottky and $\mathrm{p}-\mathrm{i}-\mathrm{n}$ diodes are employed as high-voltage rectifiers in power switching application. To suppress voltage transients when current is switched to inductive loads such as electric motors, these diodes are placed across the switching transistors. The advantage of simple metal-semiconductor diodes relative to $p-n$ junction diodes is the faster turn-off because of the absence of minority carrier storage effects and lower power dissipation during switching. Wide bandgap semiconductors such as $\mathrm{GaN}$ offer additional advantages for fabrication of diode rectifiers, including much higher breakdown voltages and operating temperatures. There is much interest in developing advanced switching devices and control circuits for CW and pulsed electrical subsystems in emerging hybrid-electric and all-electric vehicles, more-electric airplanes and naval ships and for improved transmission, distribution and quality of electric power in the utilities industry. Eventually one would like to reach target goals of $25 \mathrm{kV}$ stand-off voltage, $2 \mathrm{kA}$ or higher conducting current, forward drop less than $2 \%$ of the rated voltage and maximum operating frequency of $50 \mathrm{kHz}$. 

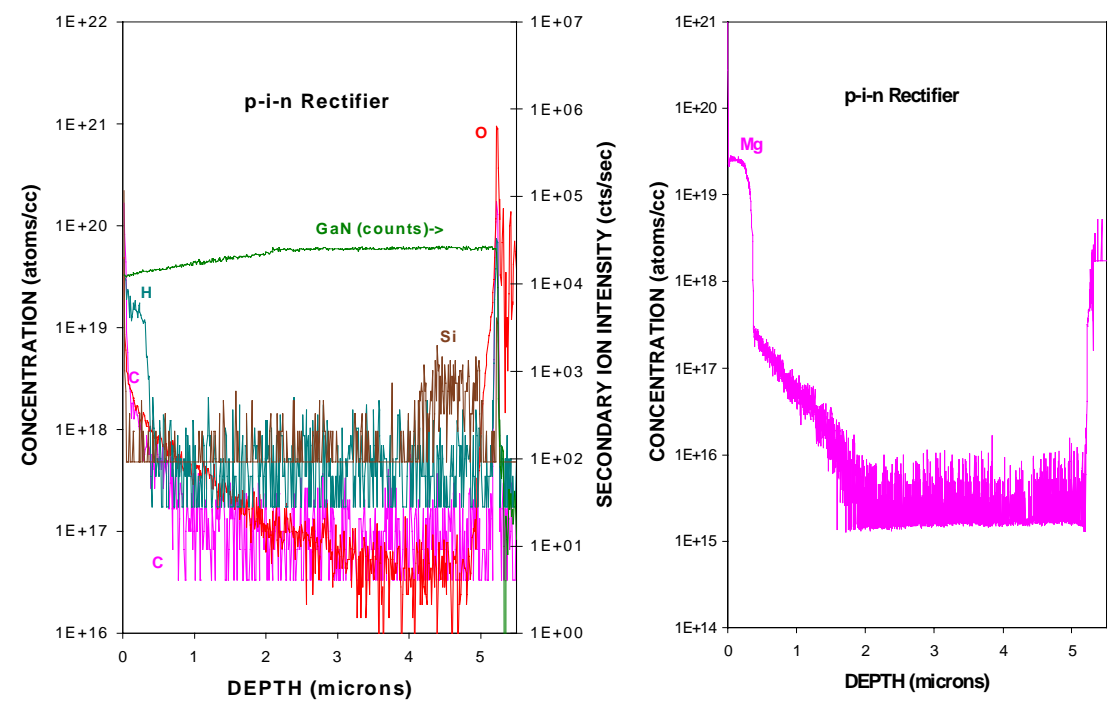

Figure 3. SIMS profiles of $\mathrm{H}$ and $\mathrm{Si}$ (left) and $\mathrm{Mg}$ (right) in an as-grown, MOCVD p-i-n rectifier structure.

Figure 3 shows a SIMS profile of $\mathrm{H}$ and other background impurities (along with intentional Si doping) in an MOCVD-grown p-i-n diode structure (left), together with the $\mathrm{Mg}$ profile in the structure (right). Notice once again that the $\mathrm{H}$ decorates the $\mathrm{Mg}$ due to formation of the neutral $(\mathrm{Mg}-\mathrm{H})^{\circ}$ complexes. About $70-80 \%$ of the $\mathrm{Mg}$ atoms have hydrogen attached.

\section{To create a}

Schottky rectifier with high breakdown voltage, one needs a thick, very pure $\mathrm{GaN}$ depletion layer. Figure 4 shows SIMS profile of $\mathrm{H}$ and other background impurities in a $2 \mu \mathrm{m}$ thick, high resistivity $\left(10^{7} \Omega \cdot \mathrm{cm}\right) \mathrm{GaN}$ layer grown by MOCVD. The reverse breakdown voltage of simple Schottky rectifiers fabricated on this material was $>2 \mathrm{kV}$, a record for GaN. Notice that in this material the hydrogen concentration is at the detection sensitivity of the SIMS apparatus. The amount of hydrogen present in $\mathrm{GaN}$ after cooldown from the growth temperature will

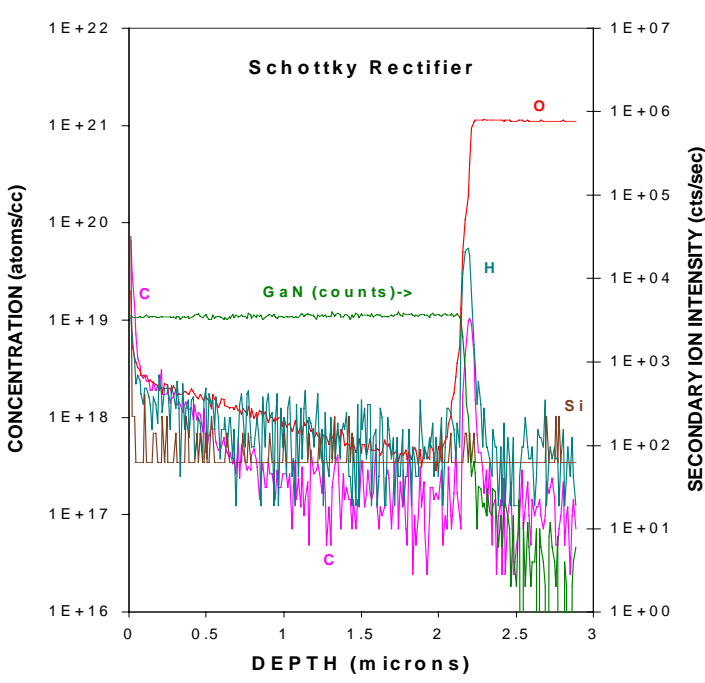

Figure 4. SIMS profiles of $\mathrm{H}$ and other background impurities in as-grown, MOCVD Schottky rectifier structure. 
depend on the number of sites to which it can bond, including dopants and point and line defects. In the absence of p-type doping, it is clear that the number of these sites is $\leq$ $8 \times 10^{17} \mathrm{~cm}^{-3}$ under our growth conditions.

Another important device for power microwave applications is the heterojunction bipolar transistor (HBTs). Several groups have reported GaN/AlGaN HBTs with gains less than 10 at room temperature. Residual hydrogen passivation of the $\mathrm{Mg}$ acceptors in the base of such devices would create instabilities in the apparent gain during operation, since minority carrier injection would lead to time-dependent dopant reactivation, i.e. the gain would show an initial exponentially decreasing current gain, which might be interpreted as a reliability problem in the absence of an understanding of the effects of hydrogen. Figure 5 shows SIMS profiles of the $\mathrm{Mg}$ (left) and $\mathrm{H}$ (right) in an as-grown GaN/AlGaN HBT structure. The hydrogen is found to decorate both the $\mathrm{GaN}(\mathrm{Mg})$ base layer at $\sim 0.4 \mu \mathrm{m}$ depth and also the $\mathrm{AlGaN}$ emitter layer, which is a region of additional strain within the structure.
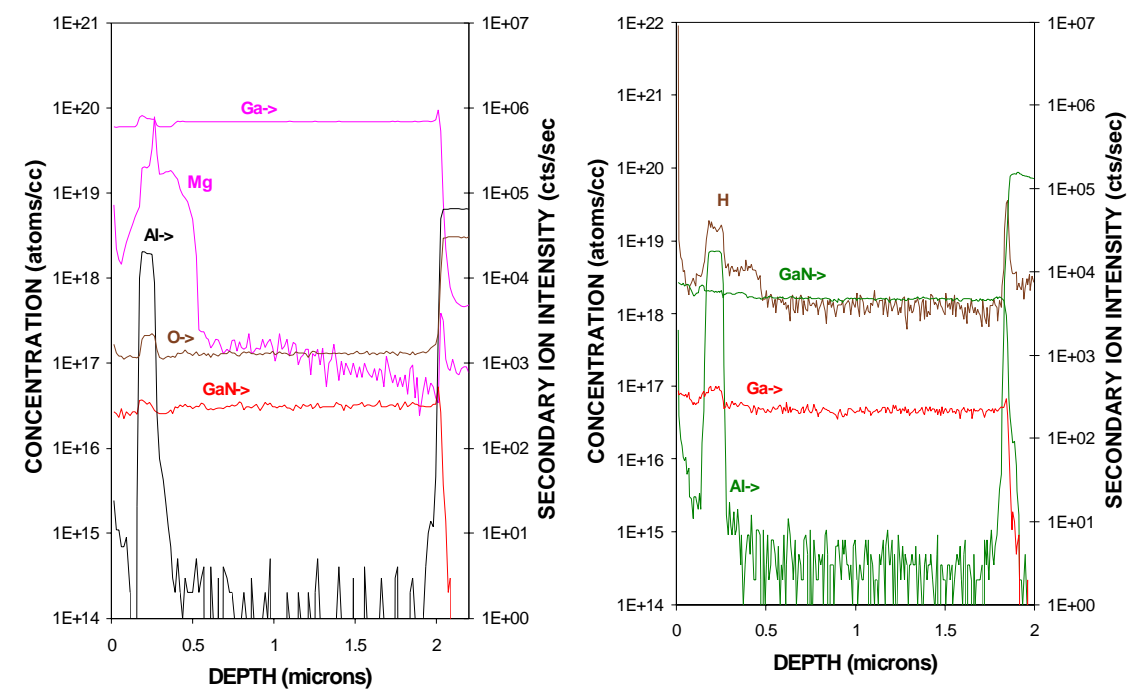

Figure 5. SIMS profiles of $\mathrm{Mg}$ (left) and $\mathrm{H}$ (right) in as-grown MOCVD GaN/AIGaN HBT structure.

Once the device structure is grown and subsequently annealed to minimize the amount of residual hydrogen, there can still be problems associated with indiffusion during device fabrication. Atomic hydrogen is found to be unintentionally incorporated into the nitrides during many processing steps, including boiling in water, dry etching, wet etching, chemical vapor deposition of dielectrics and annealing in $\mathrm{H}_{2}$ or $\mathrm{NH}_{3}$. This shows that most of wet chemical or plasma processes involved in device processing are capable of causing passivation of dopants due to hydrogen incorporation in $\mathrm{GaN}$ and related alloys. SIMS profiling of GaN exposed to hydrogen-containing gases or chemicals shows that the hydrogen can diffuse into these layers at temperatures as low as $80{ }^{\circ} \mathrm{C}$. Even though reactivation of dopants can be achieved by relatively low temperature 
thermal annealing after a given process step, the hydrogen may be cause similar problems after the subsequent processing so that one should be aware of its effects.

\section{DIFFUSION OF H IN IMPLANTED OR PLASMA-TREATED GaN}

Implantation of
protons is commonly
employed for inter-device
isolation of electronic and
photonic devices and for
current guiding in various
laser diode structures. Figure
6 shows SIMS profiles of ${ }^{2} \mathrm{H}$
implanted into n-GaN, as a
function of the subsequent
annealing temperature under a
$\mathrm{N}_{2}$ ambient. There is no
redistribution of the
deuterium until $\geq 800{ }^{\circ} \mathrm{C}$,
while at higher temperatures
the remaining ${ }^{2} \mathrm{H}$ decorates
the implant damage profile
which is slightly closer to the
surface than the atomic
profile. Note that even after a
$1200{ }^{\circ} \mathrm{C}$ anneal there is a
significant concentration of
deuterium remaining at the

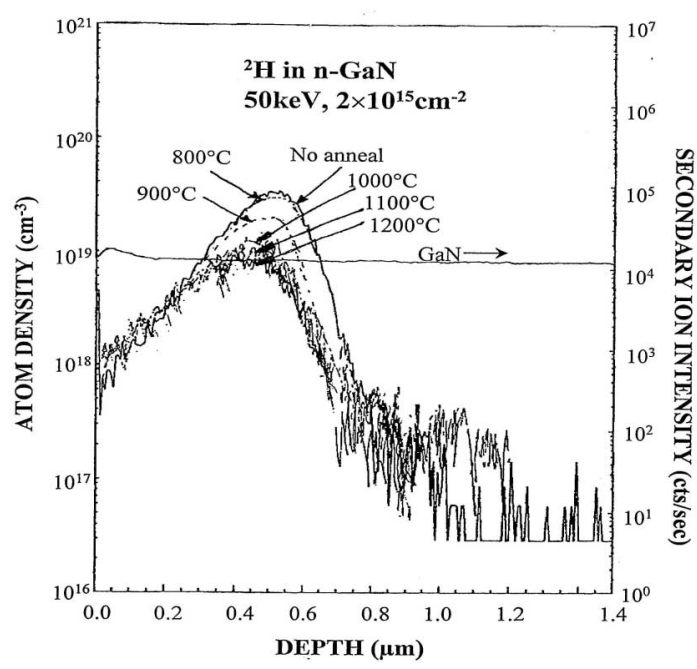

Figure 6. SIMS profiles of ${ }^{2} \mathrm{H}$ implanted into $\mathrm{n}-\mathrm{GaN}$ at a dose of $2 \times 10^{15} \mathrm{~cm}^{-2}$ and $50 \mathrm{keV}$, as a function of subsequent annealing temperature (10 secs. duration).

peak of the damage profile. It appears that after high temperature annealing the deuterium is either trapped at defects or escapes the crystal.

By sharp contrast, the redistribution of implanted ${ }^{2} \mathrm{H}$ in $\mathrm{p}-\mathrm{GaN}$ is more complicated. Figure 7 shows SIMS profiles of the deuterium as a function of annealing temperature. The redistribution begins at $\geq 500{ }^{\circ} \mathrm{C}$ and at higher temperatures there is decoration of the residual implant damage and the $\mathrm{GaN} / \mathrm{Al}_{2} \mathrm{O}_{3}$ interface, in addition to the formation of a plateau region at $\sim 0.8 \mu \mathrm{m}$ where $\mathrm{Mg}-\mathrm{H}$ complexes are the dominant species. These results show that there is competition for trapping of deuterium between different sites, including strain and defects at interfaces, Mg dopants in the GaN, damagerelated defects associated with the implant process and finally the surface of the GaN, through which the deuterium can evolve.

An example of the indiffusion of deuterium into nitrides (in this case, AlN) as a result of exposure to a ${ }^{2} \mathrm{H}$ plasma at low temperatures $\left(200\right.$ or $250{ }^{\circ} \mathrm{C}$ ) is shown in Figure 8. The deuterium has saturated the $1 \mu \mathrm{m}$ thick layer after the $250{ }^{\circ} \mathrm{C}$ exposure. This gives a rough estimate for the diffusivity as $10^{-12} \mathrm{~cm}^{2} \cdot \mathrm{sec}^{-1}$ at $250^{\circ} \mathrm{C}$. Similar values are obtained for deuterium in GaN. It is likely that the diffusivity in defect-free (bulk or homoepitaxial) nitrides is considerably lower than these values. 


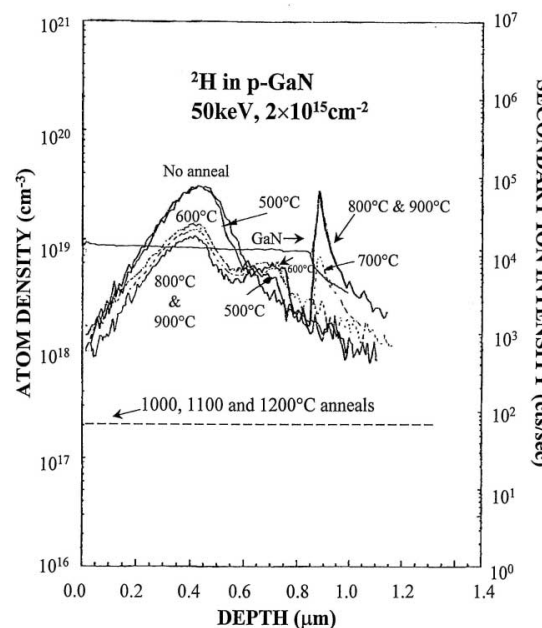

Figure 7. SIMS profiles of ${ }^{2} \mathrm{H}$ implanted into $\mathrm{p}-\mathrm{GaN}$ at a dose of $2 \times 10^{15} \mathrm{~cm}^{-2}$ and $50 \mathrm{keV}$, as a function of subsequent annealing temperature (10 secs. duration).

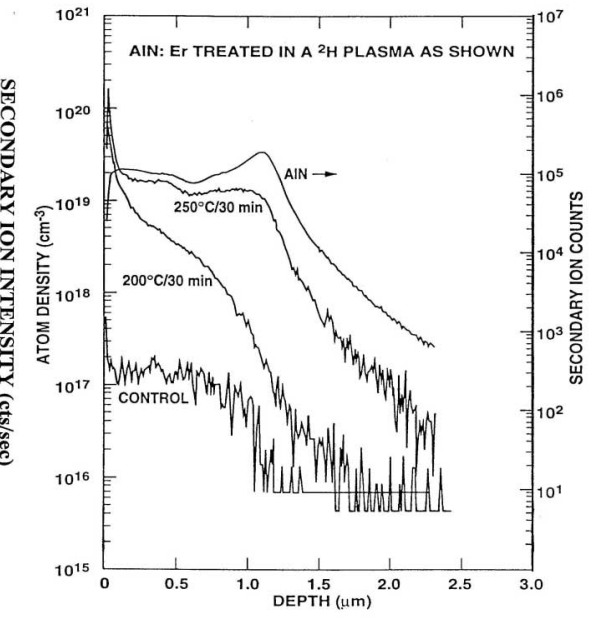

Figure 8. SIMS profiles of ${ }^{2} \mathrm{H}$ in AlN exposed to deuterium plasmas at $200{ }^{\circ} \mathrm{C}$ or $250{ }^{\circ} \mathrm{C}$ for 30 mins.

\section{SUMMARY AND CONCLUSIONS}

Hydrogen is found to bond to regions of strain in GaN-based structures, such as interfaces or defects, as well as acceptor dopants. There are many potential sources of hydrogen during growth and processing of nitrides so that one needs to be vigilant for its effects, i.e. a reduction in hole concentration with an associated increase in hole mobility. It is expected that unintentional hydrogen incorporation will play a role in $\mathrm{GaN}$ electronic devices which contain $\mathrm{p}-\mathrm{n}$ junctions, leading to high $\mathrm{p}$-contact resistances and timedependent current gains if precautions are not taken to remove the hydrogen.

\section{ACKNOWLEDGMENTS}

The work at UF is partially supported by grants from DARPA/EPRI, MDA 972-98-1-0006, monitored by ONR (J.C. Zolper) and NSF 97-32865 (L. Hess). The work at NCU is partially supported by a grant from the National Science Council of R.O.C. under contract No. NSC-88-2215-E-008-012. Sandia is a multiprogram laboratory operated by Sandia Corporation, a Lockhead-Martin Company, for the US Department of Energy under contract No. DEAC04-94-AL85000. The work of RGW is partially supported by ARL (J.M. Zavada).

\section{REFERENCES}

1. see for example, S.J. Pearton, J.C. Zolper, R.J. Shul and F. Ren, "GaN: Defects, Processing and Devices", J. Appl. Phys. 78 R1 (1999). 
2. C.G. Van de Walle, "Theory of Hydrogen is Semiconductors", Mat. Res. Soc. Symp. Proc. 51355 (1998).

3. S.M. Myers, T.J. Headly, C.R. Hills, J. Han. G.A. Petersen, C.H. Seager, W.R. Wampler, "The behavior of Ion-Implanted Hydrogen in GaN", MRS Internet J. Nitride Semicond. Res. 4S1 G5.8 (1999).

4. W.R. Wampler and S.M. Myers, "Ion Channeling Analysis of GaN Implanted with Deuterium", MRS Internet J. Nitride Semicond. Res. 4S1 G3.73 (1999).

5. M.G. Weinstein, C.Y. Song, M. Stavola, S.J. Pearton, R.G. Wilson, R.J. Shul, K.P. Killeen and M.J. Ludowise, "H Decorated Lattice Defects in Proton-Implanted GaN", Appl. Phys. Lett. 721703 (1998).

6. M.G. Weinstein, M. Stavola, C.Y. Song, C. Bozdog, H. Przbylinska, G.D. Watkins, S.J. Pearton and R.G. Wilson, "Spectroscopy of Proton-Implanted GaN", MRS Internet J. Nitride Semicond. Res. 4S1 G5.9 (1999).

7. J.M. Zavada, R.G. Wilson, C.R. Abernathy and S.J. Pearton, "Hydrogenation of GaN, AlN and InN", Appl. Phys. Lett. 642724 (1994).

8. R.G. Wilson, S.J. Pearton, C.R. Abernathy and J.M. Zavada, "Outdiffusion of deuterium from GaN, AlN and InN", J. Vac. Sci. Technol. A 13719 (1995).

9. M. Miyachi, T. Tanaka, Y. Kimura and H. Ota, "The Activation of Mg in GaN by Annealing with Minority Carrier Injection", Appl. Phys. Lett. 721101 (1998).

10. V.J.B. Torres, S. Oberg and R. Jones, "Theoretical Studies of Hydrogen Passivated Substitutional Mg Acceptor in Wurzite GaN", MRS Internet J. Nitride Semicond. Res. 235 (1997).

11. S.J. Pearton, C.R. Abernathy, C.B. Vartuli, J.W. Lee, J.D. MacKenzie, R.G. Wilson, R.J. Shul, F. Ren and J.M. Zavada, "Unintentional Hydrogenation of GaN and Related Alloys During Processing", J. Vac. Sci. Technol. A 14831 (1996).

12. Y. Ohba and A. Hatano, "Mg Doping and H Incorporation in GaN MOCVD", Jpn. J. Appl. Phys. 33 L1367 (1994).

13. J.W. Lee, S.J. Pearton, J.C. Zolper and R.A. Stall, "Hydrogen Passivation of Ca Acceptors in GaN", Appl. Phys. Lett. 682102 (1996).

14. J. Neugebauer and C.G. Van de Walle, "Role of H in Doping of GaN", Appl. Phys. Lett. 681829 (1996).

15. S.M. Myers, J. Han, T.J. Headly, C.R. Hills, G.A. Petersen, C.H. Seager, W.R. Wampler and A.F. Wright, "Behavior of Ion-Implanted Hydrogen in GaN at Concentrations $\geq 1$ at.\%", Phys. Rev. B (in press).

16. H. Harima, T. Inoue, S. Nakashima, M. Ishida and M. Taneya, "Local Vibrational Modes as a Probe of Activation Process in p-type GaN", Appl. Phys. Lett. 751383 (1999).

17. L. Sugiura, M. Suzuki and J. Nishino, "P-type Conduction in As-Grown Mg-Doped GaN Grown by MOCVD”, Appl. Phys. Lett. 721748 (1998).

18. H. Amano, M. Kito, K. Hiramatsu and I. Akasaki, Jap. J. Appl. Phys. 28 L112 (1989).

19. C.G. Van de Walle, "Interaction of Hydrogen with Native Defects in GaN", Phys. Rev. B 56 R10020 (1997).

20. S.K. Estreicher and D.M. Maric, "Theoretical Study of H in Cubic GaN", Mat. Res. Soc. Symp. Proc. 423613 (1996).

21. S. Nakamura, N. Iwasa, M. Senoh and T. Mukai, "Hole Compensation Mechanism of p-GaN Films", Jpn. J. Appl. Phys. 311258 (1992). 
22. S. Nakamura, T. Mukai, M. Senoh and N. Iwasa, "Thermal Annealing Effects on ptype, Mg-Doped GaN Films”, Jpn. J. Appl. Phys. 31 L139 (1992).

23. W. Gatz, N.H. Johnson, D.P. Bour, M.D. McCluskey and E.E. Haller, "Local Vibrational Modes of the Mg-H Acceptor Complex in GaN", Appl. Phys. Lett. 69 3725 (1996).

24. A. Bosin, V. Fiorentini and D. Vanderbilt, "H, Acceptors, and H-Acceptors Complexes in GaN", Mat. Res. Soc. Symp. Proc. 395503 (1996).

25. Y. Okamoto, M. Saito and A. Oshiyama, "First Principles Calculations on Mg and Mg-H in GaN”, Jap. J. Appl. Phys. 35 L807 (1996).

26. J.A. Van Vechten, J.D. Zook, R.D. Horning and B. Goldenberg, "Detecting Compensation in Wide Bandgap Semiconductors by Growing in $\mathrm{H}$ That is Removed by Low Temperature De-Ionizing Radiation”, Jpn. J. Appl. Phys. 313662 (1992).

27. S.J. Pearton, J.W. Lee and C. Yuan, "Minority Carrier Enhanced Passivation of HPassivated Mg in GaN", Appl. Phys. Lett. 682690 (1996).

28. see for example G. Popovici and H. Morhoe, "Growth and Doping of Defects in IIINitrides”, In GaN and Related Materials II, ed. S.J. Pearton (Gordon, Breach, NY, 1999).

29. H. Amano, I. Akasaki, T. Kozawa, N. Sawaki, K. Ikeda and Y. Ishii, "Doping of GaN with Zn", J. Lumin. 4121 (1988).

30. S.J. Pearton, C.R. Abernathy and F. Ren, "Electrical Passivation in H-PlasmaExposed GaN", Electron. Lett. 30527 (1994).

31. A. Burchaid, M. Deicher, D. Forkel-Wirth, E.E. Haller, R. Magerle, A. Prospero and R. Stotzler, "First Microscopic Observation of Cd-H Pairs in GaN", Mat. Res. Soc. Symp. Proc. 449961 (1997).

32. N.M. Johnson, W. Gotz, J. Neugebauer and C.G. Van de Walle, "Hydrogen in GaN", Mat. Res. Soc. Symp. Proc. 395723 (1996).

33. C.F. Neumark, "Defects in Wide Bandgap II-VI Crystals", Mat. Sci. Eng. R 211 (1997).

34. S.J. Pearton, J.W. Corbett and M. Stavola, Hydrogen in Crystalline Semiconductors (Springer-Verlag, Berlin 1992).

35. G. R. Antell, A.T.R. Briggs, B.P. Butler, S.A. Kitching, J.P. Stagg, A. Chew and D.E. Sykes, "Passivation of $\mathrm{Zn}$ Acceptors in InP by Atomic Hydrogen Coming from $\mathrm{AsH}_{3}$ during MOVPE”, Appl. Phys. Lett. 53758 (1988). 